\title{
The Effects of Cultural Intelligence and Transformational Leadership Style of Managers on Employee Resistance to Change
}

\author{
Fakhriyeh Hamidianpour \\ Assistant professor in Human Resources Management, Persian Gulf University, Bushehr, Iran \\ Corresponding Author: Fakhriyeh_hamidianpour@yahoo.com \\ Majid Esmaeilpour \\ Assistant professor in Business Management, Persian Gulf University, Bushehr, Iran \\ Razie Zarei \\ Graduate student of Business Management, Persian Gulf University, Bushehr, Iran
}

\section{Doi:10.5901/mjss.2016.v7n5p84}

\begin{abstract}
One of the most important challenges faced by organizations is the environmental factors' change and increasing global competitions. In response to this challenge, it should be noted that change management is a difficult task. Most of organizational changes fail. Lack of personnel's agreement with the change and their resistance are among the most important factors that cause the failure of organizational change. The objective of this study was to evaluate the effect of two factors of cultural intelligence of managers and transformational leadership style on employees' resistance to change. The population of this research includes managers and employees of Jam Petrochemical Company (Iran). The sample consisted of 260 employees and 60 managers of various units of the company. Data were collected using the tool of questionnaire. To analyze the data SMART PLS structural equation modeling software was used. The findings of this study show that cultural intelligence of managers both directly and through transformational leadership style has a positive and significant impact on the resistance to change and also the transformational leadership style has a positive and significant impact on the resistance to change.
\end{abstract}

Keywords: Transformational Leadership Style, Cultural Intelligence of Managers, Resistance to Change

\section{Introduction}

With a brief review of management literature, it is possible to see the general trend towards constant changes. Organization theorists have noted the growing process of changes in communities and organizations (Dean \& Ackerman, 2001). Change is among the most important implications of the of today's world and must be designed and managed to build constructive and effective developments in organizations. The necessity of organizational changes has made the leaders to be interested in organizations which enable people's potentials, solve the crises and emergencies (Mavidnia, 2006). The researchers believe that many organizational changes fail. This can be caused by the fact that the changes cannot be fully analyzed and the inhibiting factors of the change are not being consistently evaluated. There are many barriers to change, but what matters more than anything, is the resistance to change by managers and employees. Identifying the source of the employees' resistance to change and its influencing factors are among the most important topics studied in the current researches (Shahmohammadi, 2005). One of the factors affecting the level of staff's resistance to change is the leadership style (Schermerhorn, 1989). The selection Approach of leaders has a profound impact on organizational transformation. Personal ability of the leaders for change, change strategies selected by them, style of decision-making, communication patterns and the consequences of their behavior can strongly affect the organizational changes (Dean \& Anderson, 2001). Communication and strong leadership are a vital part in preparing any organization to change (Box, 2012).

Diverse global workplaces have created the need for culturally competent leaders (Brannen, 2016). In the companies where the leaders and staff need to decode their intentions for a set of goals and future plans, Multi-cultural conflicts happen. Transformational leadership of the twenty-first century, need inspiration, motivation and modernization plans, so that the opportunity to include a potential strategic vision for the organization is created. Staff's skill sets and 
management development, strengthen cultural intelligence (Box, 2012). Transformational leadership is one of the modern ideas in the field of organizational leadership. On the other hand the ability to communicate with employees and understand the cultural differences between them in a multicultural environment is among the key skills that managers in organizations have to have. Therefore, the ability to communicate with employees and understand the cultural differences between them is presented as a cultural intelligence (Ansari et al., 2012). The reality of today's world involves interacting with people who are culturally different. Today in business, labor, travels abroad among people of other cultures. Cultural characteristics affect the behavior of the leaders with their followers and allows managers to choose appropriate activities, especially managers of human resources, (Abzari and Khani, 2010). The researchers found that about 70 per cent of the organizational changes fail and cultural and human factors are key to this failure (Jarrett, 2003). In this study, the issue will be discussed that whether cultural intelligence of management and transformational leadership style in an environment of cultural diversity can have an impact on the strength of their followers to change. According to the teachings of cultural intelligence, and the importance of this branch of intelligence as the most efficient tool to perform tasks effectively in culturally diverse environments, as well as the consequences of proven transformational leadership in organizations, the findings may help solve the problems of many organizations to identify and strengthen the capabilities of managers in terms of proper behavior in order to reduce the resistance against change. Although recent researches on the impact of cultural intelligence on leadership's success is in the worldwide view are becoming popular, most of these studies, are review studies (library) and field studies are less. On the other hand, cultural intelligence in most of the studies done so far has been found to interact with foreign cultures, but it can be generalized to racial and ethnic subcultures within national culture as well. Iran has different ethnic cultures and multicultural interaction; this can be a reason for studying the cultural intelligence. Jam Petrochemical Company (Iran) has a workforce with cultural diversity from all over of Iran. Each of these ethnic groups has their own culture, language, dialect and customs as well as their own attitudes. The results of this can be applied in the field of human resources' management.

\section{Literature Review}

\subsection{Resistance to Change}

The change is the most important element in human life and business. Change in organizations means that the activities of the situation will turn into a different situation. Change in an organization is a process of transformation in attitudes, structures and policies of organizational units (Bolhari et al., 2010). Changes occur in all organizations and affect almost everyone in the organization. The way staff face the change is different in organizations. While some staff will gladly welcome the changes and actively participate in them, others avoid and resist as far as possible (Oreg et al., 2008). When staff is faced with major changes, perform a reactive process. According to Scott and Jeff (1988), this process consists of four steps: initial denial, resistance, gradual identification and devotion and contingent liabilities. People are unconscious and maintain defense mechanisms to protect themselves from changes and concerns arising from them. Resistance to change is the main barrier to the successful implementation of change. Resistance to change is an unavoidable natural behavioral response in addressing the threat of the organization's members (Shahmohammadi, 2005). Maurer (1996) defines change as a force of resistance that stops or slows the motion. Griffin (1993) refers to the naturalness of the concept of resistance to change and believes that it is a natural part of the organization. Staff's resistance to change, can be overt, implicit, indirect, or immediate. If people resist, in an obvious or immediate way, management will be faced with fewer problems. The worst kind of resistance is the implicit and indirect one. Implied or indirect resistance has more subtle aspects and loyalty to the organization is low (Robins, 1995). Oreg and colleagues (2008) examined the resistance to change in 17 countries, considered the resistance to change in the four dimensions:

- Routine seeking: routine seeking involves the extent to which a person is looking for stable and routine environments or enjoys these environments.

- Emotional reaction: emotional reaction reflects to an extent of stress and discomfort felt by people in response to changes.

- Short-term focus: short-term focus includes the degree to which people attend to short-term incompatibilities versus long-term interests of changing.

- Cognitive rigidity: cognitive rigidity represents some kind of tenacity and unwillingness to consider alternative ideas and perspectives. 


\subsection{Cultural Intelligence}

Various scientists have made tremendous efforts to define intelligence. Intelligence is defined as intellectual potentials (Taslimi et al., 2009). New theories about human intelligence refer to different types of intelligence. A variety of intelligence, include social intelligence, cultural intelligence, emotional intelligence, mental and physical intelligence, and verbal intelligence. Although some types of intelligences are correlated with each other in a low or moderate way, but some of them must be independent of each other (Pihlak \& Alas, 2012). Most of the challenging parts of culture are hidden. Beliefs, values, expectations, attitudes and assumptions are elements of culture that are not seen, but have an effect on people's behaviors and sometimes cause contradictory views. Therefore, effective adaptation and adjustment of cultures is needed. Cultural intelligence is the new range of intelligence is a very strong correlation with diverse working environments. Cultural intelligence is a new range of intelligence which has a very strong correlation with diverse working environments. Cultural intelligence theory combines the reality of globalization in the modern world and traditional ideas on intelligence (Ang et al., 2007). Cultural Intelligence was stated for the first time by Ang et al. (2007) who were two researchers from London Business School. They defined cultural intelligence as the ability to learn and provide correct behavioral responses to cultural patterns (Rahimi et al., 2012). They believed that people are faced with new cultural situations, can hardly find similar signs and symptoms to communicate. People should have high cultural intelligence according to the available information. Cultural intelligence is a capability that will facilitate communication. According to the developments of increasingly diverse and global business environments, it is important to be aware of cultural intelligence (Baker \& Delpechitre, 2016). Cultural intelligence is a skill that can be acquired and gives the ability of understanding a culture, growing learning about it, shaping the thinking of a person to compromise with a culture, so that the person would indicate a good behavior when dealing with other cultures (Zamani and Tabarsa, 2009). The core of the concept of cultural intelligence is the ability of individuals or social groups in engaging with constructive social interaction with individuals or social groups with different cultures (Yazdkhasti et al., 2010). From the perspective of Ang and colleagues (2007), Cultural Intelligence has four components:

- Metacognitive component: a method through which an individual argues intercultural experiences. This element addresses a process by which people gain knowledge and understand the culture. Metacognitive component is an active preparation in the intercultural interactions, modification of the previous information and knowledge and the ability to improve cognitive dimension from cultural intelligence. An example of this is when an individual uses the concepts and mental images which are not based on a real experience consistent with his/her expectations.

- Cognitive component: This dimension is defined as a general knowledge about other cultures. The cognitive component involves identifying about the similarities and differences of cultures and general knowledge about cultures. For example, information about religious beliefs, values and beliefs about the work, time, family relations, customs and language. The cultural cognitive intelligence allows the person to understand common cultural elements and use them to communicate.

- Motivational component: the confidence and trust of the person that makes him to adapt to a new culture. Motivational component indicate the volume and energy of people to interact effectively in a new cultural. The motivational component is the toughest and the most delicate part of cultural intelligence and is so similar to emotional intelligence. According to this component People only will be able to cope with cultural interactions if they receive a great deal of motivation and believe in their own ability.

- Behavioral component: the ability to display appropriate verbal and nonverbal actions to interact with people from different cultures. Cultural intelligence is the behavioral aspect manifested in human behavior, and may indicate the individual's willingness to enter into the inner world of people with different cultures (Rafieyan, 2016).

\subsection{Transformational Leadership Style}

Transformational leadership theory was first described by Burns (1978). Burns distinguished between transactional and transformational leadership. He defines transformational leadership as a process in which leaders and followers each day are led to higher levels of motivation and morality. Transformational leadership raises needs and motives of followers and highlights the changes in individuals, groups and organizations. Transformational leaders can stimulate followers, have the ability to inspire, earn commitment of followers and can change beliefs, attitudes, emotions and goals of individuals and organizations. Transformational leaders are capable of uniting the followers based on their abilities to change the 
objectives and beliefs. Transformational leaders create the feeling in subordinates that they are respected human beings and help them see things in a new way. Meanwhile, the transactional leaders address the current needs of their subordinates and have a great attention to purchase (Najjar, 2012). Burns (1978) indicated that transformational leaders are those who possess vision and challenge others to do exceptional things and make efforts. Only transformational leaders are able to show essential courses for new organizations. Because they are the sources of changes and master the changes at (Muhammadalinejad, 2012). Following Burns' researches (1978), in the field of transformational leadership, Bass (1985) provided a model of leadership that prescribed transactional and transformational leadership models for stable and transformational situations of an organization respectively. Bass believed that a transformational leader is the one that strengthens the organization's performance and establishes a positive relationship with subordinates, encourages employees to exceed the individual needs and work in a way that guarantees the desires of groups and organizations. Transformational leaders provoke their subordinates to do what they can (Yaqoubi et al., 2010). In this study, the dimensions of transformational leadership are regarded from Bass' perspectives (1985) as a conceptual framework of transformational leadership. These dimensions are:

- Idealized influence: a spiritual impression in the eyes of followers is the main step in the transformational leadership. Unquestioned loyalty and respect of the followers towards the leader create an idealized feeling. It makes people consider the leader as a model for their own behavior. These components make the transformational leaders be admired and respected.

- Inspirational motivation: Implies motivations and inspirations of followers by appealing to their inner feelings and motives. This is done by showing empathy and optimism, engaging followers in providing future prospects and having high expectations of them.

- Intellectual stimulation: it is a form of an open dialogue regarding the process of formation and implementation of the landscapes. In fact, transformational leaders stimulate the followers to explore serious ways, rethink about visions and the problems in achieving the goals. They use Intellectual stimulation to challenge thoughts, imagination and creativity of their followers. This requires that leaders while encouraging followers, provide a new and creative approach to getting things done and make the followers to re-examine the traditional ways of solving problems.

- Individual considerations: means understanding and respecting individual differences of followers, association with each one of them and the stimulation of them by delegating responsibilities to them to make them learn more. The transformational leader communicates separately with each of followers to find out the needs, skills and ambitions of them. The leaders act as a mentor and teacher and develop the followers to achieve higher levels of their capacity (Zarei, 2014).

\subsection{The Empirical Literature}

In terms of research topics, different researches in Iran and other countries have been conducted which some of them have been addressed in the following. Rahimi et al. (2012) conducted a study entitled "Assessment of cultural intelligence of managers of federations in the country and evaluation of its relationship with transformational leadership style". The results showed that cultural intelligence can be a predictive variable of leadership. Given the positive relationship between cultural intelligence and transformational leadership style, their results, emphasized the need to regard the cultural intelligence of managers to have a better efficiency. Davis (2009) in a study titled "Evaluation of cultural intelligence of managers of military forces ", knows intelligence culture as an essential competence of a leader and argues that cultural intelligence is one of the fundamental aspects of leadership development and the ability for all the leaders of the military, including officers and unofficial members. Oreg and Berson (2011) carried out a study entitled "Leadership and employee response to change: the role of personal characteristics and leadership style of transformational leaders". Their findings suggest that the behavior of transformational leadership moderates the relationship between employees' status and is an objective of resistance to change. The purpose of employees to resist organizational change is related to the admissions of managers in changing the values and behaviors of transformational leadership. Lugo (2007) did a study entitled "Cultural and emotional intelligence in the development of the global transformational leadership skills"; he checked the strength and dimensions of cultural and emotional intelligence and transformational leadership skills. The results showed that there was a positive significant relationship between social and personal aspects of transformational leadership and emotional cultural intelligence skills. A Summary of researches in the field of our research variables and their interrelationships is presented In Table 1. 
Table 1: literature of the relationship between transformational leadership style, cultural intelligence and resistance to change

\begin{tabular}{|c|c|c|}
\hline Researchers & The title of the study & Finding \\
\hline $\begin{array}{l}\text { Moshabaki and } \\
\text { Tizro (2009) }\end{array}$ & $\begin{array}{l}\text { The impact of Emotional and } \\
\text { cultural intelligence on the success } \\
\text { of leaders in world-class }\end{array}$ & $\begin{array}{l}\text { The findings showed that cultural intelligence has a positive effect on the } \\
\text { success of world class leaders. World class leaders encounter different cultures } \\
\text { in their work environment with employees or customers. So having high cultural } \\
\text { intelligence can help them to communicate with employees and customers. }\end{array}$ \\
\hline 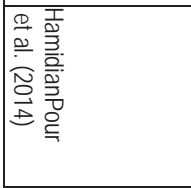 & $\begin{array}{l}\text { Investigating the relationship } \\
\text { between transformational and } \\
\text { transactional leadership style with } \\
\text { employee's resistance to change }\end{array}$ & $\begin{array}{l}\text { Transformational and transactional leadership style and employee's resistance to } \\
\text { change are related. Also there is a significant negative correlation between the } \\
\text { three components of transformational leadership (idealized influence, intellectual } \\
\text { stimulation, individual consideration) and two components of transactional } \\
\text { leadership (exception-based management and conditional bonuses) and } \\
\text { employee's resistance to change,. }\end{array}$ \\
\hline $\begin{array}{l}\text { Kana and Parry } \\
(2004)\end{array}$ & $\begin{array}{l}\text { Identifying a paradox: the basic } \\
\text { theory of leadership in overcoming } \\
\text { resistance to change }\end{array}$ & $\begin{array}{l}\text { In this study using grounded theory the New Zealand nurses were discussed in } \\
\text { terms of their management. The results of the study, showed high levels of } \\
\text { transformational leadership in nursing leadership. It also showed that } \\
\text { organizational politics act as a facilitator of the relationship between } \\
\text { transformational leadership style and resistance to change. }\end{array}$ \\
\hline $\begin{array}{l}\text { Pihlak \& Alas } \\
(2012)\end{array}$ & $\begin{array}{l}\text { Resistance to change in, Hindi, } \\
\text { Chinese and Estonian } \\
\text { organizations }\end{array}$ & $\begin{array}{l}\text { This research examined the effect of national culture on the resistance to change } \\
\text { in three countries: India, China and Estonia. The findings showed that the cause } \\
\text { of resistance mainly in Hindi and Estonian organizations was fear, but in the } \\
\text { Chinese organizations was inertia. Negative factor of stress increased during } \\
\text { experiments of change management projects in all three countries. Stress } \\
\text { increased the leadership problems in India and increased workload in Estonia. } \\
\text { To overcome resistance to change, communication was used in India and } \\
\text { training with communications was used in China and Estonia. }\end{array}$ \\
\hline Box (2012) & $\begin{array}{l}\text { Cultural intelligence and } \\
\text { transformational leadership among } \\
\text { managers }\end{array}$ & $\begin{array}{l}\text { The results showed how companies can improve performance through the } \\
\text { development of transformational leadership and cultural intelligence. }\end{array}$ \\
\hline Ansari et al. (2012) & $\begin{array}{l}\text { Analysis of the relationship } \\
\text { between cultural intelligence and } \\
\text { transformational leadership (Case } \\
\text { study: business managers) }\end{array}$ & $\begin{array}{l}\text { The results showed a positive and significant relationship between cultural } \\
\text { intelligence and transformational leadership. Also there existed a significant } \\
\text { positive correlation between each of the dimensions of cultural intelligence and } \\
\text { transformational leadership. Therefore, cultural intelligence is a key factor (stem) } \\
\text { in transformational leadership. In addition, the results showed that teams having } \\
\text { diversity and the ability to create conflicts can use Cultural intelligence for } \\
\text { effective transformational leaderships. }\end{array}$ \\
\hline $\begin{array}{l}\text { Keung and } \\
\text { Rockinson (2013) }\end{array}$ & $\begin{array}{l}\text { The relationship between } \\
\text { transformational leadership and } \\
\text { cultural intelligence: A Study of } \\
\text { International School leaders }\end{array}$ & $\begin{array}{l}\text { The results show that there is a positive relationship between cultural intelligence } \\
\text { and transformational leadership in the international school leaders. Leaders who } \\
\text { have a higher level of cultural intelligence, showed a higher level of } \\
\text { transformational leadership style. So, people with high cultural intelligence were } \\
\text { capable of leading and managing multi-cultural environments effectively. }\end{array}$ \\
\hline Lee et al. (2013) & $\begin{array}{l}\text { The effects of social support and } \\
\text { leadership in compatibility and } \\
\text { performance in abroad: The } \\
\text { moderating role of social } \\
\text { experience and cultural intelligence }\end{array}$ & $\begin{array}{l}\text { The results showed that transformational leadership had a significant contribution } \\
\text { in the adaptation of social protection in abroad And the moderating role of social } \\
\text { experience and cultural intelligence were also confirmed in this study. }\end{array}$ \\
\hline
\end{tabular}

Source: Provided by authors

\subsection{Hypotheses and Conceptual Model}

This research aims to examine the impact of cultural intelligence of managers on employees' resistance to change through transformational leadership style. By studying the theoretical and empirical literature on research topic, and taking into account the results of Rahimi and colleagues (2012), Davis (2009), Oreg and Berson (2011), Lugo (2007), Moshabaki and Tizro (2009), Hamidianpour et al. (2014), Kana and Parry (2004), Pihlak and Alas (2012), Ansari et al. (2012), Keung and Rockinson (2013) and Lee et al. (2013), the following hypotheses were formulated and tested using data collection tools.

$H_{1}$ : Cultural intelligence of managers has an impact on transformational leadership style.

$\mathrm{H}_{2}$ : Cultural intelligence of managers has an impact on employee's resistance to change.

$H_{3}$ : Transformational leadership style has an impact on employees' resistance to change. 
Model and conceptual framework of this study was designed by revealing the fundamental variables of the subject of the study and linking them through theoretical and empirical literature. The conceptual framework of this research is provided in the figure (1). In this study, the model of Oreg and colleagues (2008) was used for the variable of resistance to change, and the model of Ang et al. (2007) were used for the evaluation of cultural intelligence and the model of Bass (1985) was used to evaluate transformational leadership style.

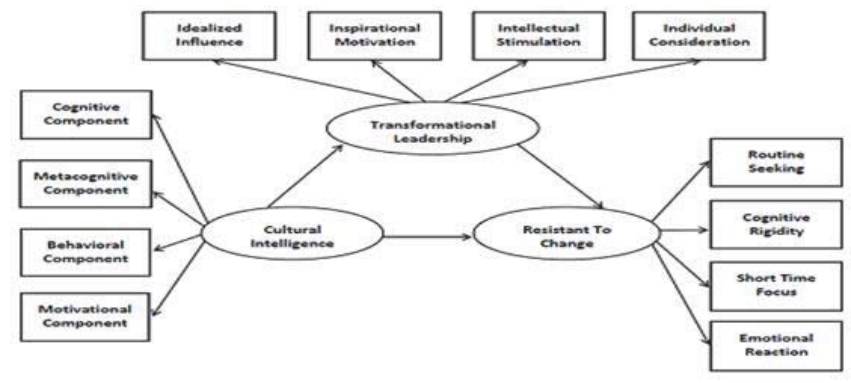

Figure 1: Research Conceptual Model

\section{Methodology}

In terms of the results, the present study is an applied one and in terms of the nature it is descriptive and correlation. The study population comprises managers and employees of Jam Petrochemical Company. According to the received information, the number of population is 815 people. The sample size was determined to be 260 people using formula Cochran's limited population at 95\% confident level, with 50\% agreement ration and agreeing and 5\% level of sampling error. According to the list of the population, in this study, stratified random sampling method was used. A total of 300 questionnaires were distributed among employees and 150 questionnaires were distributed among the directors in person and finally 260 questionnaires of staffs and 60 questionnaires of managers were returned with a favorable response.

Data were collected by questionnaires. Questionnaire consisted of three parts, which include the introduction, the demographic questions and questions related to the measurement of the variables. To measure the variables of the study, 66 questions were designed through a combination of questionnaires and other researchers associated with the research. Scale variables in this study, was the five-item Likert scale (from strongly agree to strongly disagree). Table 2 provides information on the design of the questionnaire. Given that the questionnaire for this study was designed using studies of other researchers its validity was measured before; therefore, we can say that the questionnaire is valid. But despite this, to determine the validity of the questionnaire, formal content validity was used as well. So the designed questionnaire was given to a number of professors in the field of human resource management, change management and managers and experts of Jam Petrochemical Company and they were asked to express their opinion about the validity. After collecting comments, the final questionnaire was designed. To examine the reliability, the most common method for assessing the reliability of the questionnaire, namely the Cronbach's alpha coefficient was used. Cronbach's alpha coefficient was higher than 0.7 for all variables and for the entire questionnaire was $88 \%$, which is an acceptable coefficient and suggests that the reliability of the questionnaire is at an appropriate level. In addition, the validity of the questions of the questionnaire was determined by the average variance extracted (AVE) and to assess the reliability of the questionnaire, the composite reliability coefficient (CR) was used. Table 2 shows the results of validity and reliability indices.

Table 2: Variables and the resources of extraction of indices and the reliability results of the data collection tool

\begin{tabular}{|c|c|c|c|c|c|c|}
\hline Main variables & $\begin{array}{l}\text { Main variables' } \\
\text { dimensions }\end{array}$ & $\begin{array}{l}\text { The number of } \\
\text { questions }\end{array}$ & $\begin{array}{l}\text { Extraction source of the } \\
\text { questions }\end{array}$ & AVE & CR & $\begin{array}{c}\text { Cronbach alpha } \\
\text { coefficient }\end{array}$ \\
\hline \multirow{4}{*}{ Cultural intelligence } & Metacognitive component & 4 & \multirow{4}{*}{$\begin{array}{l}\text { Cultural Intelligence } \\
\text { Center (2005) }\end{array}$} & 0.51 & 0.81 & 0.72 \\
\hline & Cognitive component & 6 & & 0.59 & 0.81 & 0.71 \\
\hline & Motivational component & 5 & & 0.55 & 0.86 & 0.82 \\
\hline & Behavioral component & 5 & & 0.51 & 0.84 & 0.76 \\
\hline
\end{tabular}




\begin{tabular}{|c|c|c|c|c|c|c|}
\hline \multirow{4}{*}{$\begin{array}{l}\text { Transformational } \\
\text { leadership }\end{array}$} & Idealized influence & 6 & \multirow{4}{*}{ Bass (1985) } & 0.57 & 0.89 & 0.85 \\
\hline & Inspirational motivation & 9 & & 0.64 & 0.83 & 0.74 \\
\hline & Intellectual stimulation & 7 & & 0.57 & 0.89 & 0.85 \\
\hline & Individual considerations & 7 & & 0.64 & 0.83 & 0.74 \\
\hline \multirow{4}{*}{$\begin{array}{l}\text { Resistance to } \\
\text { change }\end{array}$} & Routine seeking & 5 & \multirow{4}{*}{ Pardo et al. (2003) } & 0.51 & 0.81 & 0.72 \\
\hline & Emotional reaction & 4 & & 0.59 & 0.81 & 0.71 \\
\hline & Short-term focus & 4 & & 0.55 & 0.86 & 0.82 \\
\hline & Cognitive rigidity & 4 & & 0.51 & 0.84 & 0.76 \\
\hline Total questionnaire & & 66 & & & & $88 \%$ \\
\hline
\end{tabular}

Source: Provided by authors

In order to calculate the convergent validity, AVE criteria were used and In order to calculate reliability CR criteria was used. If AVE equaled at least 0.5 , it will indicate that the variables possess good convergent validity. This means that a hidden variable is able to explain more than half of the variances can be (observed variables) (Hair et al., 2011; Fornell, \& Larcker, 1981). Due to the fact that in this study, an average variance extracted (AVE) for all variables is higher than 0.5. Therefore, convergent validity of the verification model is confirmed. Composite reliability coefficient (CR) and Cronbach's alpha coefficient, measure reliability of measurement tools. As Table 2 shows, since the coefficient of the composite reliability $(\mathrm{CR})$ and alpha coefficient for all variables are greater than 0.7 , the reliability of the questions in the questionnaire are accepted.

To test the hypotheses and conceptual model of the study, structural equation modeling (Partial Least Squares) was used by software smart PLS. The reason for the use of the software smart PLS was the small size of the sample compared to the number of items of the questionnaire. AMOS and LISREL applications that are sensitive to the sample size, cannot be used to test the research's conceptual model.

\section{Research Findings and Discussion}

\subsection{Descriptive Results of the Data}

To analyze the data, descriptive statistics were used to analyze demographic variables. Table 3 is related to demographic variables through the collection of 320 questionnaires.

Table 3: Demographic characteristics of respondents

\begin{tabular}{|l|l|c|}
\hline Demographic variable & Levels & Percentage of frequency \\
\hline \multirow{2}{*}{ Gender } & Male & 94.2 \\
& Female & 5.8 \\
\hline \multirow{3}{*}{ Education } & Diploma and lower & 20.2 \\
& Associate & 16.3 \\
& Undergraduate & 47.4 \\
& Graduate and higher & 15.9 \\
\hline \multirow{4}{*}{ Age } & 20 to 30 years & 29.08 \\
& 31 to 40 years & 65.35 \\
& 41 to 50 years & 3.98 \\
& Over 50 years & 1.59 \\
\hline
\end{tabular}

Source: Provided by authors.

As Table 3 shows the largest number of respondents are man with a 94.2 percent, the highest level of respondents are undergraduate with 47.7 percent And the respondents' age ranged from 31 to 40 years with 65.35 percent.

\subsection{Testing the conceptual model}

Conceptual model and research hypotheses were tested by structural equation modeling through smart PLS software. In structural equation modeling, all variables were classified into two categories of hidden and observed variables. Observed or viewed variables (rectangles) were directly measured by the investigator, while the hidden or latent variables (oval) 
were not directly measured, but were inferred on the basis of the correlations between measured variables. Latent variables represent some theoretical constructs that are not visible directly and are observed through other observed variables. Figures 2 and 3 indicate the model in the estimation of standard path coefficient and significant coefficients.

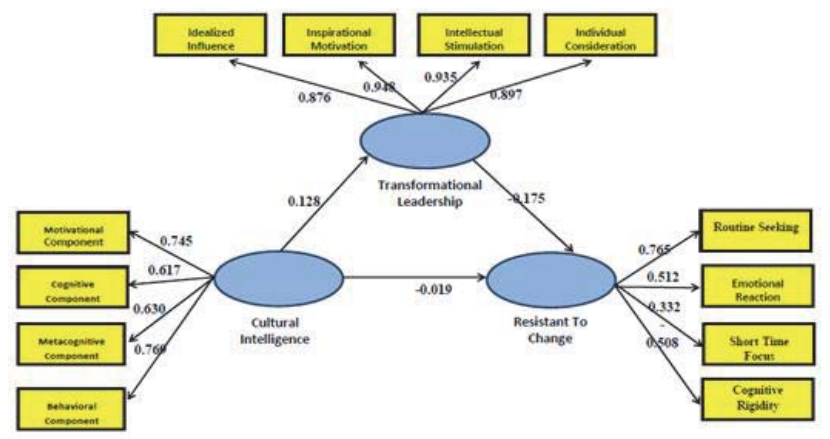

Figure 2: Confirmatory factor analysis, measurement and structural model with standardized coefficients values

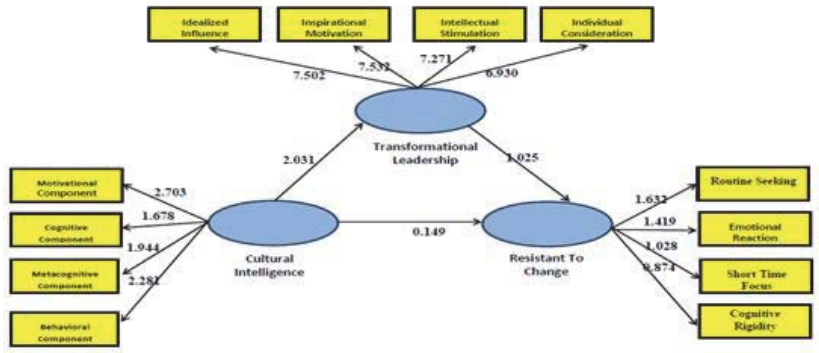

Figure 3: Confirmatory factor analysis, measurement and structural models, along with some significant coefficients (tvalue)

Figure 3 shows the different version of the model through significant factor in absolute values (|t-value|). In fact, all the equations of the model (load factor) and structural equation modeling (path) are tested using the t statistics. According to this model, if the $t$ value is greater than 1.96 for paths, the load factor and the path factor will be significant at $95 \%$. If the $t$ value is less than 1.96 for paths, the load factor and the path factor will not be significant. If the $t$ value is more than 2.58 , the load factor and the path factor will be significant at $99 \%$.

Fit Indices of the model are one of the most important steps in the analysis of structural equation modeling. These indices answer this question that whether the model represented by the data, confirms the conceptual model? By running tests of structural equation modeling through PLS software, we realize that this software offers the fit indices to show the alleged conceptual model is fitted with the experimental data. Unlike conventional statistical analysis, a statistic that are approved or rejected, the structural equation modeling to evaluate the fit of the model are a set of indices. Unlike conventional statistical analysis, which are approved or rejected by one statistic, a set of indices are defined in the structural equation modeling to evaluate the fit of the model. However, in practice the use of four or five indices is enough. The results of quality indices (suitability) of model are shown in table (4).

Table 4: Indicators conceptual model fit in the implementation of structural equation modeling

\begin{tabular}{|l|c|c|c|c|c|c|c|}
\hline Index model fitting & $\mathrm{X} / \mathrm{DF}$ & $\mathrm{P}$ & $\mathrm{CFI}$ & $\mathrm{NFI}$ & $\mathrm{RMSEA}$ & $\mathrm{IFI}$ & $\mathrm{RFI}$ \\
\hline Acceptable fit & $\leq 1 \leq 3$ & $\geq 0.05$ & $\geq 0.9$ & $\geq 0.9$ & $\leq 0.09$ & $\geq 0.9$ & $\geq 0.9$ \\
\hline Obtained Value & 2.194 & 0.671 & 1.000 & 0.913 & 0.004 & 1.000 & 0.924 \\
\hline
\end{tabular}

Source: Provided by authors. 
Data of Table 4 shows that the mentioned indices of the research were in good condition and this implies that the data fits. Thus, according to data derived from the implementation of structural equation modeling, the conceptual model was approved. Approval of the conceptual model does not mean that all relations have been approved in the model. After the overall fit of the model, the relations of the model must also be tested to find out whether the relations are defined in the approved version or not? After extracting data from the confirmatory factor analysis, we can test the main hypothesis of the research. According to the results of standardized path coefficient and significant coefficients or t statistics (Figure 2 and 3), it can be said that cultural intelligence of managers at $95 \%$ has a significant positive impact on transformational leadership style. But the variable of cultural intelligence of managers at $95 \%$ had no significant effect of the staff's resistance. Also according to the obtained coefficient at 95\%, variable of transformational leadership style had no significant effect on the resistance of staff. Table 5 summarizes the results of tests.

Table 5: Testing the main hypotheses of the study

\author{
Hypotheses \\ $\boldsymbol{H}_{1}$ : Cultural intelligence of managers has an impact on \\ transformational leadership style. \\ $\boldsymbol{H}_{2}$ : Cultural intelligence of managers has an impact on \\ employee's resistance to change. \\ $H_{3}$ : Transformational leadership style has an impact on \\ employees' resistance to change.
}

$\begin{array}{cccc}\text { Standardized path coefficient } & \text { T-value } & \text { P-value } & \text { Result } \\ 0.128 & 2.031 & 0.000 & \text { Accepted } \\ -0.019 & 0.149 & 0.000 & \text { Rejected } \\ -0.176 & 0.025 & 0.097 & \text { Rejected }\end{array}$

Source: Provided by authors.

\section{Conclusions and Recommendations}

In today's world, organizations are increasingly faced with dynamic and changing environment and inevitably have to adapt to environmental factors (Brannen, 2016). However, statistics indicate that two-thirds of organizational changes fail and the most important factor in the success and failure of these changes is the human factor (Jarrett, 2003). A lot of researches have been conducted to determine the factors influencing resistance. The researchers intend to identify the factors controlling resistance to change in order to improve their changes. Therefore this study attempted to identify the influence of two relatively new variables in the field of management being cultural intelligence and transformational leadership style on the resistance to change. Therefore, based on previous studies in the field, theory and conceptual model were designed. Using the questionnaire, data were collected through structural equation modeling and with the use of software smart PLS, and then assumptions and conceptual model were tested. As Table 5 shows, the findings of this study indicate a significant positive relationship between cultural intelligence and the impact of transformational leadership style. The findings of the study were consistent with the results of Rahimi et al. (2012), Box (2012), Ansari et al. (2012), Lugo and colleagues (2013). In all of these studies a significant positive relationship was confirmed between cultural intelligence management and transformational leadership style. According to the results obtained from Table 5, it can be said that cultural intelligence of managers does not affect the employee resistance to change at 95 percent confidence level. In researches of Rahimi et al. (2012) and Lugo and colleagues (2013) there was no significant relationship between these two variables as well. Also, according to the results of the study, transformational leadership style of managers does not affect the employees' resistance to change at the 95 percent confidence level. This finding contradicts the results of Hamidianpour et al. (2014), Oreg and Berson (2011). According to the researchers, there is a significant negative relationship between transformational leadership and employees' resistance to change. The reason for rejecting this hypothesis in this study may be due to the neutralization of the impact of transformational leadership style on the resistance to change. Which is may be resulted from Interference of other personal, organizational, group factors or governing relations between those working in the research and those who have not being examined in this study.

Since the analysis of research data approved the impact of cultural intelligence of managers on transformational leadership style and the current organizations need leaders who can adapt to increasing environmental changes, we can suggest this issue as a solution to attract managers. Organizations can attract managers with high cultural intelligence, and create a good development within them.

Unlike other intelligences, cultural intelligence can be trained; organizations can set up cross-cultural training classes for managers and train managers who are culturally intelligent. In this study, although the impact of cultural intelligence on employees' resistance to change was not approved but the negative path coefficient suggests a negative 
relationship between these two variables. So having managers who are culturally intelligent will reduce the resistance of employees to change. Cultural intelligence training of managers in this regard can be somewhat effective. The path coefficient showed a negative relationship in the impact of transformational leadership style on employees' resistance to change. So organizations can employ the transformational leaders to reduce staff's resistance to change.

All researches are faced with limitations. One limitation of this study is in the data collection tools. However questionnaire as one of the most common data collection tools of research in the social and behavioral sciences has its inherent limitations. The population of this study was limited to managers and employees of Jam Petrochemical Company (Iran) and since the number of sample is small the extension of the results of the research must be done cautiously. Another limitation of this study is the little familiarity of number of managers and employees of Jam Petrochemical Company with some of the concepts related to the research. However, to overcome this limitation, the questionnaires were distributed by researchers and the questions were explained to them, the low levels of familiarity with the concepts related to research on questionnaires may affect the results.

\section{References}

Abzari, M. And Khani, a. (2010). Cultural Intelligence, dealing with differences. Journal of Management Era, 4(4), 16-37.

Anderson, D. \& Ackerman-Anderson, L. S. (2001). Beyond change management: advanced strategiesfor today's transformational leaders. San Francisco, Jossey-Bass/Pfeiffer, 236.

Ang, S; Van Dyne \& L; Koh, C. (2007). Culturallntelligence: Its Measurement and Effects on Cultural Judgment andDecision Making, Cultural Adaptation and Task Performance. Management and Organization Review. 3(3); 335.

Ansari M.I , Radmehr R \& Shalikar M (2012). Analysis the Relationship between Cultural Intelligence and Transformational Leadership (The Case of Managers at the trade office). International Journal of Business and Social Science. 3 (14), 137-152.

Baker D.S \& Delpechitre d (2016). An Innovative Approach to Teaching Cultural Intelligence in Personal Selling, Journal for Advancement of Marketing Education, 24(1), 77-87.

Bass, B. M. (1985). Leadership and Performance Beyond Expectations. New York: The Free Press.

Bolhari, A .; Latifi, a. And Soleimon Purian, b. (2010). Change Management Framework in the development of human resource planning systems. The first Iranian Student Conference on Information Technology, No. 170, 18-21.

Box, J.B (2012). The Relationship between Cultural Intelligence and Transformational Leadership Among Managers. Available at SSRN: http://ssrn.com/abstract=2011856

Brannen, C. (2016). The relationship between cultural intelligence and transformational leadership: A study of people leaders, The University of the Rockies, 2016, №. 122, 31-76.

Burns, J.M, (1978). Leadership, N.Y, Harper and Raw.

Davis K.D (2009). Cultural Intelligence and Leadership: An Introduction for Canadian Forces Leaders. Kingston, Ontario, Canadian Defence Academy Press, 157.

Dean . A \& Anderson L. (2001). BeyondChangeManagement. Library of Congress Cataloging-in-Publication Data.

Griffin, W.; Woodman, W., \& Sawyer, E. (1993). Toward a Theory of Organizational Creativity, The Academy of Management Review, 18(2), 293-321.

Fornell, C., \& Larcker, D. (1981). Evaluating structural equation models with unobservable variables and measurement error. Journal of Marketing Research, 18(3), 39-50.

Hair, F., Ringle M., \& Sarstedt, M. (2011). PLS-SEM: Indeed a Silver Bullet. Journal of Marketing Theory and Practice, 19(2 ), 139-152.

Hamidian Pour, F .; Zarei, r. And Hasiri, Z. (2014). Investigation of the relationship between transformational and transactional leadership style with employees' resistance to change. International Conference on Development and Business Excellence.

Jarrett, M. (2003). The Seven Myths of Change Management. Business Strategy Review, 14(4), 73-97.

Kana. M \& Parry K.W(2004). Identifying paradox: A grounded theory of leadership in overcoming resistance to change. The Leadership Quarterly, 15(2), 467-491.

Keung K., \& Rockinson, A. (2013). The relationship between transformational leadership and cultural intelligence : A study of international school leaders. Journal of Educational Administration, 51(6), 836 - 854.

Lee L.Y, Veasna S \& Wu W.Y, (2013). The effects of social support and transformational leadership on expatriate adjustment and performance: The moderating roles of socialization experience and cultural intelligence. Career Development International, 18(4), $377-415$.

Lugo, V. ( 2007). An Examination of cultural and emotional intelligences in the development of global transformational leadership skills. Doctoral Dissertation. Walden University, 149-187. Online: http://ut.pr/biblioteca/Glossa2/Journal/Oct2011/EmotionalIntelligences.pdf

Maurer, R. (1996). Beyond the Wall of Resistance: Unconventional Strategies that Build Support for Change. Bard Books, Inc., Austin, TX.

Mavidnia, F. (2006). Management and transformational leadership. Monthly devise Title, No. 167, $23-27$.

Moshabaki, A. Tizro A,. (2009). Emotional intelligence and cultural intelligence in leadership success. Management Researches, 4(3), 73-53.

Muhammadalinejad, H. (2012). The relationship between transformational leadership and employee empowerment in Urmia University 
Jihad. Master's thesis Urmia University Faculty of Literature and Humanities.

Najjar, M. (2012). The relationship between emotional intelligence and transformational leadership between the administrative managers of Kashmar. Master's thesis, Faculty of Humanities, Islamic Azad University of Shahroud.

Oreg, S \& Berson, Y .(2011). Leadership and Employees' Reaction to Change: The Roll of Leaders' Personal Attributes and Transformational Leadership Style. Personnel Psychology, 64(2), 627-659.

Oreg, S . Bayazıt , M. Vakola , M. Arciniega, L. Armenakis, A. Barkauskiene, R . Bozionelos, N . Fujimoto, Y . González, L \& Han , J. (2008). Dispositional Resistance to Change: Measurement Equivalence and the Link to Personal Values Across 17 Nations. Journal of Applied Psychology, 93(4), 935-944

Pardo, D.; Val, M., \& Martinez, F. (2003). Resistance to change: a literaturereview and empirical study. Management Decision, 41(21), 148-155.

Pihlak U \& Alas R, (2012). Resistance to change in Indian, Chinese and Estonian organizations. Journal of Indian Business Research, $4(4), 224-243$.

Rafieyan, V . (2016). Relationship between Cultural Intelligence and Translation of Culture-Bound Texts, Journal of Applied Linguistics and Language Research, 3(3), 2016, pp. 173-184. www.jallr.com ISSN: 2376-760X

Rahimi, M .; Keshti dar M. And Khoshbakhti, J. (2012). An assessment of cultural intelligence of the managers in federations of the country and its relationship with transformational leadership style, Sports Studies, 14(2), 191-208.

Robins, A. (1995). The Management of Organizational Behavior. Translation of Parsaeian and Arabi, vol. 3, Tehran: Institute of Business Studies and Research.

Schermerhorn, J. (1989). Management for Productivity, John Wiley \& Sons, New York ,NY.

Shahmohammadi, P. (2005). Reducing resistance to change by applying Theory of Constraints. Third International Conference on Management, Tehran.

Taslimi, M.s .; Gholipour, A .; Verdi Nejad, F. And Aleagha, M. (2009). Strategies to promote Cultural Intelligence of managers in international affairs. Research Management, 2(4), 57-29.

Yaqobi, NM .; Moghaddami, m., And Keykha, A. (2010). The relationship between transformational leadership and organizational citizenship behavior. Research a Change Management, 2(4), 64-96.

Yazdkhasti, G .; Qasemi, V. And Vhida, F. (2011). The relationship between cross-cultural contacts and cultural intelligence, theoretical analysis. Quarterly Cultural Research, 4(12), 133-162.

Zamani, A., \& Tabarsa, Q. (2009). Cultural Intelligence, a New Competence of Managers. Tadbir Monthly, No. 213, 49-53. 